\title{
A preliminary study of excess mortality using a psychiatric case register
}

\author{
CHRISTINE HASSALL, ${ }^{1}$ P PRIOR, ${ }^{2}$ AND K W CROSS ${ }^{2}$ \\ From the Department of Psychiatry, ${ }^{I}$ University of Birmingham, Birmingham B15 2TJ; and the Department of \\ Social Medicine, ${ }^{2}$ University of Birmingham.
}

SUMMARY Systematic screening of death certificates referable to residents of two health districts covered by a psychiatric case register allows the study of excess mortality in unselected psychiatric patients from a defined area of known population. Deaths among the case register patients exceeded those expected by $80 \%$; the relative risk was maximal during the first year after registration and was significantly raised in both sexes and in patients of all age-groups. Patients may be selected by service use and by diagnostic group: the excess mortality of "inpatients" both in relative and absolute terms exceeded that of "outpatients". For dementia patients both the relative risk and more notably the absolute risk was high, and the excess mortality was significantly raised in both sexes and all age-groups. It was again greatest during the first year after registration. Deaths of patients with schizophrenia and paranoid psychosis exceeded those expected by 40 per cent and the excess was limited to the first year after registration and occurred predominantly among men.

The excess mortality of psychiatric patients as compared with that of a general population has been demonstrated in a number of studies which have recently been reviewed by Sims. ${ }^{1}$ However, these studies have usually been concerned with selected groups of psychiatric patients such as discharged inpatients ${ }^{2}$ or those with a particular diagnosis. ${ }^{4-6}$

Psychiatric case registers, allied to systematic screening of all death certificates for persons resident in areas covered by such registers, offer unique opportunities to carry out mortality studies of large series of unselected psychiatric patients from defined geographical areas with known populations. Patient information recorded also allows analysis by service use and diagnostic group.

The Worcester Psychiatric Case Register ${ }^{7}$ was set up and funded by the D.H.S.S. in 1972, its function being to monitor the effect of a new community psychiatric service known as the Worcester Development Project. $^{8}$ It is a computerised record of all patients using the (ten) psychiatric services provided by Worcester and Kidderminster Health Districts on and after 1st January 1973. These two districts have a combined population of approximately 324000 of whom 263700 persons are aged 15 and over. By the end of 1985 there were some 20000 patients on the Register.

It was clear from the inception of the Register that it would be necessary to keep a close check on patients who died. As it was the practice for local hospitals to receive copies of death certificates for all persons living within the two Health Districts, it was convenient to include the Case Register in this arrangement so that the certificates could be screened by the Register staff for psychiatric patients and the records amended. It is possible that some deaths were missed, for instance, any patients who had moved away from the area. However, the number must be small because, apart from the formal information gathering, health and social services staff in a community-based service have many contacts in the community and gather information on an informal basis. Such information was fed back to the Case Register Office where it could be checked and entered into the system.

\section{Material and methods}

This study is concerned with patients aged 15 years or over registered between 1974-83. The exclusion of registrations in 1973 has removed the long-term residents of the local mental hospital from the series, which therefore represents, for the most part, those patients making their first contact with the psychiatric services.

Of the total of 13530 patients, 4896 experienced at least one episode of psychiatric inpatient care ("inpatients") either alone or in conjunction with other services, and the remaining 8634 were treated 
entirely within the community based services ("outpatients"). Separate analyses have been carried out of these two groups and also for patients with: (i) dementia (1047); (ii) schizophrenia and paranoid psychosis (695), irrespective of the type of care received.

The numbers of deaths that might be expected to occur in a given series were computed from sex- and age-specific "person years at risk" (pyr) and sex- and age-specific mortality rates for England and Wales. The rates were derived from deaths for 1969-1973 and 1979-1983 and from census population figures for 1971 and 1981 as denominators. Two summary indices were used to assess the risk of mortality in the series: a standardised mortality ratio (SMR) obtained from observed/expected numbers, and an excess mortality rate (EMR) defined as (observed minus expected/1000 pyr.) The former is a measure of the risk of death in the patient series relative to the risk in the general population of the same sex and age constitution; the latter is a measure of the proportion of patients dying from causes which might be attributable to the illness or factors associated with it.

The initial analysis considered annual intervals from registration and 5-year age-groups, age being that at registration. The results have been summarised for three time intervals and three age-ranges in the tables.

Significance testing for individual SMRs assumed that the observed numbers followed a Poisson distribution. Exact Poisson probabilities were computed for small observed numbers. For larger numbers the distribution was assumed to approximate the Normal (i.e. $\mathrm{SE}=$ mean). The $95 \%$ confidence intervals for SMRs were computed based on Byar's approximation; $\chi^{2}$ analysis was used to test the difference between SMRs. Confidence limits of EMRs were computed from the $95 \%$ confidence intervals of the observed minus expected number, assuming this number to be a Poisson variable.

\section{Results}

The data which form the basis for this study are given in table 1; for patients in each of the five analytical groups distributions are given by: years since registration (table 1A); sex (table 1B); age-group (table 1C).

\section{TOTAL SERIES}

Taking the series as a whole, there was an $80 \%$ increase in mortality compared with the general population (table $2 \mathrm{~A}$ ). The highest relative risk (3.0) was found in the first year after registration and over the next four years the relative risk was still significantly elevated. After 5 years the risk of dying was very close to that of the general population. The annual excess death rate was 34 per 1000 pyr for the first year decreasing to only 8 per 1000 pyr during the next four years.

There was little difference between men and women either in relative risk or in excess mortality (table 2B).

The SMRs for patients in all three age ranges were significantly raised, with the maximum value occurring for patients under 45 years (table 2C). However, the excess mortality rate was negligible for this age-group and increased sharply with age to a value of 64 per 1000 pyr for patients 65 years of age and over.

\section{"INPATIENTS"}

The patterns of risk were essentially the same as for the total series but with increased SMRs and EMRs. The latter decreased from 61 per 1000 pyr during the first year after registration to only 2 per 1000 pyr after five years (table 2A).

Table 1 Distribution of patients by analytical group

\begin{tabular}{|c|c|c|c|c|c|}
\hline Group & All patients & Inpatients & Outpatients & Dementia & $\begin{array}{l}\text { Schizophrenia and } \\
\text { paranoid psychosis }\end{array}$ \\
\hline \multicolumn{6}{|c|}{$\begin{array}{l}\text { A. By interval from } \\
\text { registration } \\
\text { (years) }\end{array}$} \\
\hline $\begin{array}{l}<1 \\
1-4\end{array}$ & $\begin{array}{l}13530 \\
11309\end{array}$ & $\begin{array}{l}4896 \\
4061\end{array}$ & $\begin{array}{l}8634 \\
7248\end{array}$ & $\begin{array}{r}1047 \\
632\end{array}$ & $\begin{array}{l}695 \\
606\end{array}$ \\
\hline $5+$ & 5358 & 1977 & 3381 & $\begin{array}{l}0.32 \\
126\end{array}$ & 343 \\
\hline \multicolumn{6}{|l|}{ B. By sex } \\
\hline Male & 5576 & 2051 & 3525 & 363 & 295 \\
\hline Female & 7954 & 2845 & 5109 & 684 & 400 \\
\hline \multicolumn{6}{|c|}{$\begin{array}{l}\text { C. By age at } \\
\text { registration } \\
\text { (years) }\end{array}$} \\
\hline 45 & 7663 & 2067 & 5596 & 21 & 341 \\
\hline $45-64$ & 3102 & 1300 & 1802 & 73 & 216 \\
\hline $65+$ & 2765 & 1529 & 1236 & 953 & 138 \\
\hline
\end{tabular}


Table 2 Mortality in psychiatric patients by patient status ( $O=$ observed deaths; $E=$ expected deaths)

\begin{tabular}{|c|c|c|c|c|c|c|c|c|c|c|c|c|}
\hline \multirow[b]{3}{*}{$\begin{array}{l}\text { A. By interval from } \\
\text { registration } \\
\text { (years) }\end{array}$} & \multicolumn{9}{|c|}{ Standardised mortality ratios (SMR) } & \multicolumn{3}{|c|}{$\begin{array}{l}\text { Excess mortality rates } \\
(/ 1000 \text { pyr })\end{array}$} \\
\hline & \multicolumn{3}{|c|}{ All patients } & \multicolumn{3}{|c|}{ Inpatients } & \multicolumn{3}{|c|}{ Outpatients } & \multirow{2}{*}{$\begin{array}{l}\text { All } \\
\text { EMR }\end{array}$} & \multirow{2}{*}{$\begin{array}{l}\text { Inpatient } \\
\text { EMR }\end{array}$} & \multirow{2}{*}{$\begin{array}{l}\text { Outpatient } \\
\text { EMR }\end{array}$} \\
\hline & $\mathbf{O}$ & $\mathbf{E}$ & SMR & $\mathbf{O}$ & $\mathbf{E}$ & SMR & $\mathbf{0}$ & $\mathbf{E}$ & SMR & & & \\
\hline$<1$ & 613 & 195.6 & $3.0 \ddagger$ & 374 & 102.3 & $3.7 \ddagger$ & 239 & $93 \cdot 3$ & $2 \cdot 6 \ddagger$ & 34 & 61 & 18 \\
\hline $1-4$ & 691 & 437.5 & $1.6 \ddagger$ & 443 & 233.9 & $1.9 \ddagger$ & 248 & 203.6 & $1.2+$ & 8 & 18 & 2 \\
\hline $5+$ & 157 & $177 \cdot 2$ & 0.9 & 102 & 90.5 & $1 \cdot 1$ & 55 & $86 \cdot 7$ & $0 \cdot 6$ & 0 & 2 & 0 \\
\hline Total & 1461 & $810 \cdot 3$ & $1.8 \ddagger$ & 919 & $426 \cdot 7$ & $2 \cdot 2 \ddagger$ & 542 & 383.6 & $1 \cdot 4 \ddagger$ & 11 & 23 & 4 \\
\hline \multicolumn{13}{|l|}{ B. By sex } \\
\hline Male & 630 & $326 \cdot 4$ & $1.9 \ddagger$ & 413 & 175.0 & $2.4 \ddagger$ & 217 & 151.4 & $1.4 \ddagger$ & 13 & 27 & 4 \\
\hline Female & 831 & 483.8 & $1.7 \ddagger$ & 506 & $251 \cdot 7$ & $2 \cdot 0 \ddagger$ & 325 & $232 \cdot 1$ & $1.4 \ddagger$ & 10 & 20 & 4 \\
\hline \multicolumn{13}{|l|}{$\begin{array}{l}\text { C. By age at } \\
\text { registration } \\
\text { (years) }\end{array}$} \\
\hline$<45$ & 106 & $46 \cdot 1$ & $2 \cdot 3 \ddagger$ & 48 & 14.6 & $3.3 \ddagger$ & 58 & 31.5 & $1.8 \ddagger$ & 2 & 2 & 1 \\
\hline $45-64$ & 252 & $165 \cdot 3$ & $1.5 f$ & 157 & 78.0 & $2.0 \ddagger$ & 95 & $87 \cdot 3$ & $1 \cdot 1$ & 6 & 13 & 1 \\
\hline $65+$ & 1103 & 598.9 & $1.8 t$ & 714 & 334.1 & $2 \cdot 1 \ddagger$ & 389 & 264.8 & $1.5 \ddagger$ & 64 & 86 & 36 \\
\hline
\end{tabular}

$\dagger<0.01 ; \ddagger<0.001$ (2-tailed tests)

Table 3 Mortality in psychiatric patients by diagnostic group ( $O=$ observed deaths; $E=$ expected deaths)

\begin{tabular}{|c|c|c|c|c|c|c|c|c|}
\hline \multirow[b]{3}{*}{$\begin{array}{l}\text { A. By interval from } \\
\text { registration } \\
\text { (years) }\end{array}$} & \multicolumn{6}{|c|}{ Standardised mortality ratios (SMR) } & \multicolumn{2}{|c|}{$\begin{array}{l}\text { Excess mortality rates } \\
\text { (/1000 pyr) }\end{array}$} \\
\hline & \multicolumn{3}{|c|}{ Dementia } & \multicolumn{3}{|c|}{ Schiz and paranoid psyc. } & \multirow{2}{*}{$\begin{array}{l}\text { Dementia } \\
\text { EMR }\end{array}$} & \multirow{2}{*}{$\begin{array}{l}\text { Schiz and paranoid psyc. } \\
\text { EMR }\end{array}$} \\
\hline & $\mathbf{0}$ & $\mathbf{E}$ & SMR & $\mathbf{O}$ & $\mathbf{E}$ & SMR & & \\
\hline$<1$ & 240 & 65.7 & $3.7 \ddagger$ & 26 & $10 \cdot 1$ & $2.6 \ddagger$ & 210 & 24 \\
\hline $1-4$ & 250 & $106 \cdot 1$ & $2.4 \ddagger$ & 31 & $27 \cdot 4$ & $1 \cdot 1$ & 110 & 2 \\
\hline $5+$ & 34 & $25 \cdot 0$ & $1 \cdot 4$ & 11 & $10 \cdot 7$ & $1 \cdot 0$ & 36 & - \\
\hline Total & 524 & $196 \cdot 8$ & $2 \cdot 7 \ddagger$ & 68 & $48 \cdot 3$ & $1.4 \dagger$ & 138 & 6 \\
\hline \multicolumn{9}{|l|}{ B. By sex } \\
\hline Male & 207 & 68.0 & $3 \cdot 0 \ddagger$ & 21 & 6.4 & $3 \cdot 3 t$ & 183 & 10 \\
\hline Female & 317 & $128 \cdot 8$ & $2 \cdot 5 \ddagger$ & 47 & $32 \cdot 8$ & $1 \cdot 4^{*}$ & 116 & 7 \\
\hline \multicolumn{9}{|l|}{$\begin{array}{l}\text { C. By age at } \\
\text { registration } \\
\text { (years) }\end{array}$} \\
\hline$<45$ & 6 & 0.1 & $60 \cdot 6 \ddagger$ & 8 & 2.6 & $3 \cdot 1^{*}$ & 105 & 3 \\
\hline $45-64$ & 23 & $5 \cdot 1$ & $4 \cdot 5 \ddagger$ & 9 & 13.2 & 0.7 & 61 & - \\
\hline $65+$ & 495 & 191.5 & $2 \cdot 6 \ddagger$ & 51 & 32.5 & $1.6+$ & 150 & 40 \\
\hline
\end{tabular}

* <0.05; $+<0.01 ; \quad \ddagger<0.001$ (2-tailed tests)

The SMRs were highly significant for all age-groups with a maximum occurring in the youngest age group; EMRs increased with age reaching a level of 86 per 1000 pyr for patients over 65 years of age (table $2 \mathrm{C}$ ).

\section{"OUTPATIENTS"}

Overall there was a $40 \%$ increase in mortality compared with the general population, and the highest relative risk (2.6) was found in the first year after registration; the excess mortality rate was negligible except for this period (table 2A). Over all years there was no difference between SMRs or between EMRs for men and women (table 2B). When SMRs were considered by age group, highly significant results were obtained for the youngest and oldest groups (table 2C). However, the excess mortality rate for the former was only 1 per 1000 pyr as compared with 36 per 1000 pyr for patients aged 65 years and over.

\section{DEMENTIA PATIENTS}

For patients with this diagnosis the overall relative risk (2.7) was very highly significant and the SMRs decreased from 3.7 for the first year to 1.4 for the period 5 years or more after registration. In the first year the excess mortality rate was 210 per 1000 pyr (equivalent to 1 in 5 patients), falling to 110 per 1000 pyr during years 1-4 (table 3A). The SMR and EMR values for men were significantly greater than the 
corresponding values for women (table 3B). Although SMRs decreased with increasing age, the EMR for patients aged 45-64 (61 per 1000 pyr) was less than the values for the youngest and oldest age-groups (table 3C).

\section{PATIENTS WITH SCHIZOPHRENIA AND PARANOID PSYCHOSIS}

For all patients there was a 40 per cent increase in deaths as compared with the general population. A significantly high SMR was obtained only during the first year following registration, and the excess mortality rate was negligible except for this period (table 3A). Overall the SMR for men (3.3) was significantly greater than that for women $(1 \cdot 4)$ (table 3B). The SMRs for patients under 45 years $(3 \cdot 1)$ and for those 65 years or over (1.6) were both significant; however, the excess mortality rate for the former age-group was negligible whereas that for the latter was 40 per 1000 pyr (table $3 \mathrm{C}$ ).

\section{Discussion}

This preliminary study has demonstrated the excess mortality of a total unselected population of psychiatric patients who, for the most part, made their first contact with the psychiatric services during the ten-year period. Deaths exceeded those expected from the experience of the general population by $80 \%$. The relative risk was greater during the first year after registration and thereafter decreased so that after five years the risk of dying was virtually the same as that of the general population. The relative risk of death was significantly raised in both sexes, in patients of all age-groups, and especially in patients under 45 years of age. However, the proportion of patients dying from causes which might be attributable to the psychiatric illness or factors associated with it was negligible for this age group and sharply increased with age.

These patterns of risk were replicated in both the "inpatient" and "outpatient" series, except that there was no increased relative risk for "outpatients" aged 45-64 years. Excess mortality in "inpatients" exceeded that in "outpatients", both in relative and absolute terms. This result presumably reflects the greater severity of morbidity in the former group and the fact that many more "outpatients" made only a single contact with the psychiatric services.

The findings for the two diagnostic groups which have been used here for illustrative purposes provide an interesting contrast. The pattern of excess mortality among dementia patients was similar to that of the total series described above, although the relative and more notably the absolute risks were especially high. On the other hand, patients with schizophrenia and paranoid psychosis had a high relative risk only for the first year after registration, and the risk for males exceeded that for females. The absolute risk was negligible for patients under 65 years of age, and that for the oldest-age-group was only about one-quarter of the corresponding value for dementia patients.

Comparisons with results from other studies are often difficult to make because of differing diagnostic definitions, age and sex distributions, periods of study and of follow-up, and methods of selection of patients. For example, it might be expected that our study would be comparable to that of Herrman et al ${ }^{6}$ who analysed the mortality of schizophrenic patients identified from the Oxford Psychiatric Case Register between 1971 and 1973. However, although they used a similar data base they included a standing inpatient population in their study, which was carried out over an earlier period and had a different balance of "inpatients" and "outpatients".

Further analysis of our large data base would enable several legitimate comparisons to be made; and it is hoped that causes of death can be obtained so that the high excess mortality of patients during the first year after registration, and of patients under 45 years of age, can be investigated. It seems likely, for example, that suicide would prove to be a major factor in the excess for younger patients. The apparent deficit of deaths among "outpatients" after 5 years of followup, and of patients aged 45-64 years with a diagnosis of schizophrenia and paranoid psychosis, also merits further study.

Correspondence to: Dr. K W Cross, Department of Social Medicine, University of Birmingham, Birmingham B15 2TJ.

\section{References}

${ }^{1}$ Sims ACP. Why the excess mortality from psychiatric illness? Br Med J 1987; 294: 986-7.

${ }^{2}$ Craig TJ. Mortality among psychiatric inpatients. Age adjusted comparison of populations before and after psychotropic drug era. Arch Gen Psychiatry 1981; 38: 935-8.

${ }^{3}$ Sangstad LF, Odegard O. Mortality in psychiatric hospitals in Norway. Acta Psychiatr Scand 1979; 43: 431-47.

${ }^{4}$ Sims ACP, Prior MP. Arteriosclerosis-related deaths in severe neurosis. Compr Psychiatry 1980; 23: 181-5.

${ }^{5}$ Kendler KL. A twin study of mortality in schizophrenia and neurosis. Arch Gen Psychiatry 1986; 43: 643-9.

${ }^{6}$ Herrman HE, Baldwin JA, Christie D. A record-linked study of mortality and general hospital discharge inpatients diagnosed as schizophrenic. Psychol Med 1983; 13: $581-593$.

${ }^{7}$ Hassall C, Stilwell JA. Family doctor support for patients on a psychiatric case register. J R Coll Gen Pract 1977; 27: 605-8.

${ }^{8}$ Hassall C. The Worcester Development Project. Int J Ment Health 1976; 5(3): 44-50.

Accepted for publication April 1988 